\title{
MANDIBULAR PARAMETERS ON CBCT AND PANORAMIC RADIOGRAPH AS PREDICTORS FOR AGE AND GENDER IN EGYPTIAN POPULATION
}

\author{
Radi M Kumper* and Mahmoud T El-Destawy**
}

\begin{abstract}
Objective: This study aimed at evaluating the mandibular parameters as predictors for the gender and age using CBCT and panoramic radiograph.

Materials and methods: Imaging exam records of 98 patients aged between 20 and 50 years, including Panoramic images and $\mathrm{CBCT}$ were selected. Selection was based on the exclusion of images with any kind of pathologic condition and fractures in the mandible.

Results: Ramus height and gonial angel were used to differentiate females from males and estimate their ages. CBCT showed a statistically significant difference compared to panoramic radiography in Ramus height and gonial angel. In CBCT, when the ramus height was $>61.5 \mathrm{~mm}$ it indicated the gender as females. When the Bigonial width was $>155^{\circ} \mathrm{mm}$ it indicated the gender as females. When the Gonial angel was $\geq 132^{\circ}$ it indicated females. Concerning estimation of individuals ages in CBCT, when the ramous height was $>61.5 \mathrm{~mm}$ it indicated $\leq 30$ years old. When the Bigonial width was $>155^{\circ} \mathrm{mm}$ it indicated $\leq 30$ years old. On the other hand, when the Gonial angel was $\geq 132^{\circ}$ it indicated $\leq 30$ years old.
\end{abstract}

Conclusion: Bigonial width and the Gonial angel on CBCT might differentiate females from males and predict different ages in a more superior and reliable way compared to panoramic view.

\section{INTRODUCTION}

The mandible is the second most durable bone of the body and is the most resilient in unfavourable conditions. The angle of mandible is formed by the tangent lines of the posterior border of the ramus and the base of the mandible. It is an important landmark of the mandible and is commonly used in forensic science for age, race and sex identification ${ }^{(1,2)}$.

The morphological changes undergone by the mandible are thought to be influenced by dental status, gender and the age of the patient ${ }^{(3)}$. The identification and actual location of various anatomical structures in the mandible are of a great importance ${ }^{(4)}$. Various remodeling fields in the mandible specially the gonial region, antegonial region, condyle and ramus undergo morphological changes throughout the individual's life $^{(5)}$. These changes can be easily evaluated and studied in dried mandible as well as on radiographs ${ }^{(6)}$. The mandibular morphological measurements such as gonial angle, ramus height and Bigonial width have been evaluated by Several longitudinal studies ${ }^{(7,8)}$.

The gonial angle is formed by the line tangent to the lower border of the mandible and the line tangent to the distal border of the ascending ramus and condyle ${ }^{(9,10)}$. The shape of the mandibular base, especially the gonial angle, correlates with the function and shape of the muscles of mastication ${ }^{(11)}$. With age, the masticatory muscles change in function and structure, expressed by decreased contractile activity and lower muscle density ${ }^{(12)}$. Some studies

\footnotetext{
* Ass. Professor, Faculty of Dental Medicine, Department of Periodontology, Al Azhar University, Cairo, Egypt.

** Lecturer, Faculty of Dental Medicine, Department of Periodontology, Al Azhar University, Cairo, Egypt.
} 
have shown a gender difference related to the mandibular angle's size and morphology ${ }^{(9,13)}$. The effect of the individual age and gender on the size of the gonial angle is controversial. Although, some studies have shown a widening of the gonial angle with the increasing age ${ }^{(9,14)}$, many other panoramic radiographic studies have reported different results $(13,15,16)$. In spite of, most of the studies in edentulous subjects have indicated a wider angle in female subjects ${ }^{(13,15,17)}$, this finding has not been confirmed in some other studies ${ }^{(9,16)}$.

There was no significant change with regard to Bigonial width or ramus breadth across age groups for either gender ${ }^{(18)}$. Ramus, mandibular body hight and mandibular body length decreased significantly for both genders, whereas the mandibular angle increased significantly for both genders with increasing age ${ }^{(19)}$.

Forensic medicine has used some radiographic techniques as an auxiliary method in discovery of unidentified bodies' postmortem ${ }^{(23)}$. Panoramic $\mathrm{X}$-ray technology, image processing and analyzing techniques allow quantification of mandibular bone. In addition, these radiographies allow a bilateral view and are adequate to inform on vertical measurements of the mandible ${ }^{(20,21)}$. This is the main reason for using them for asymmetry evaluation of the condylar and the ramus process and for measuring vertical differences between both sides ${ }^{(22)}$. Cone beam computed tomography (CBCT) is a relatively new CT system that focuses on the head and neck. Although, it has been reported on the important benefits of CT assisting coroners, CBCT uses an X-ray beam and a detector system that move around the part of the body under examination. It is the test of choice in dentistry and has the advantage of much lower cost and smaller size of the equipment without losing reliability and accuracy of the image ${ }^{(24-28)}$.

With the above-mentioned background and the knowledge that panoramic x-ray and CBCT are commonly used in dental practice, thus the present study was conducted to compare some mandibular parameters on both types of radiographs as predictors for age and gender in Egyptian population.

\section{SUBJECTS AND METHODS}

Imaging exam records of 98 patients aged between 20 and 50 years, including Panoramic images and CBCT were selected from databases at the Department of Oral medicine, Periodontology, Oral Diagnosis and Radiology, Faculty of Dentistry, Al-Azhar University. Selections based on exclusion of images with any kind of pathologic condition and fractures in the mandible.

\section{Radiographic measurements Fig (1-5):}

Gonial angles were measured by using a method described by Mattila et al. ${ }^{(29)}$. A line will be digitally traced on the images tangential to the most inferior points at the gonial angle and the lower border of the mandibular body and another line tangential to the posterior borders of the ramus and the condyle. The insertion of these two lines forms the Gonial angle, which was measured on the right and left sides of the mandible. Ramus heights were measured using a method described by Saini et al. ${ }^{(8)}$. Aline represents the ramus which extended from the most superior lateral point to the most inferior lateral point on the ramus tangent. Ramus hight was measured on both sides on each image. Bigonial width is the distance between both Gonia. The Gonian is the most inferior, posterior and lateral point on the external angle of the mandible ${ }^{(18)}$. It is measured horizontally from the right to the left Gonia.

\section{RESULTS}

\section{Statistical analysis of the data}

Power analysis indicated 98 subjects (male and female) would be sufficient to demonstrate statistical significance at $\mathrm{p}<0.05$ level with a power of (at least) $\geq 80 \%$. According to the following formula: 


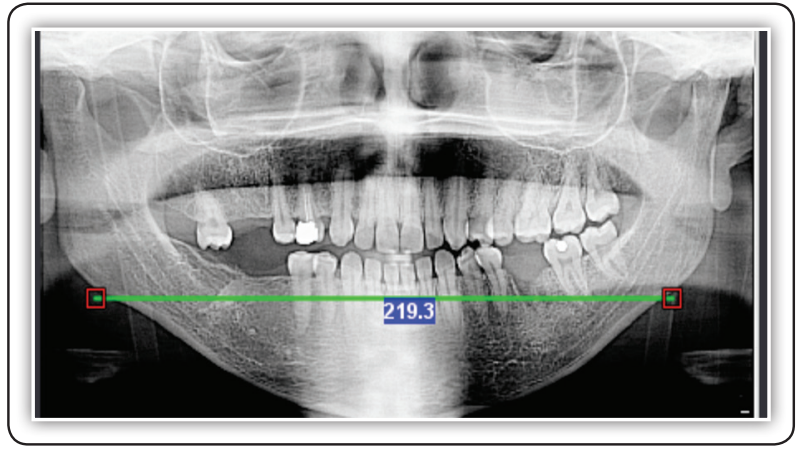

FIG (1) Panoramic view shows Bigonial width

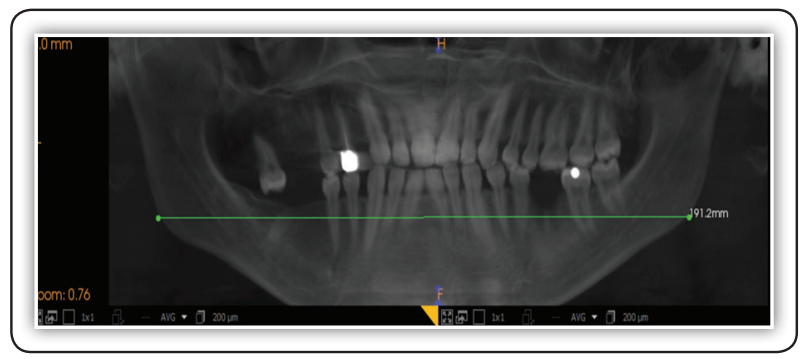

FIG (3) CBCT shows Bigonial width

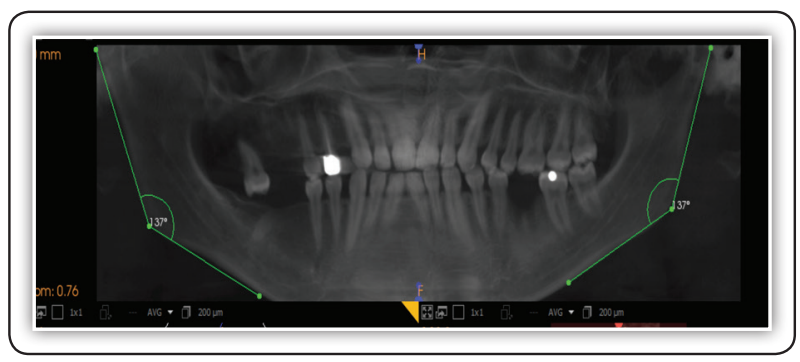

FIG (5) CBCT shows Gonial angle

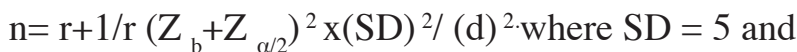
$\mathrm{d}=2$. Data were fed to the computer and analyzed using IBM SPSS software package version 20.0. (Armonk, NY: IBM Corp). The KolmogorovSmirnov, Shapiro and D'Agostino tests were used to verify the normality of distribution of variables. Student t-test was used to compare two groups for normally distributed quantitative variables while Paired t-test was used to compare two periods. Receiver operating characteristic curve (ROC) was used to determine the diagnostic performance of the markers. Area more than 50\% gives acceptable performance and area about $100 \%$ is the

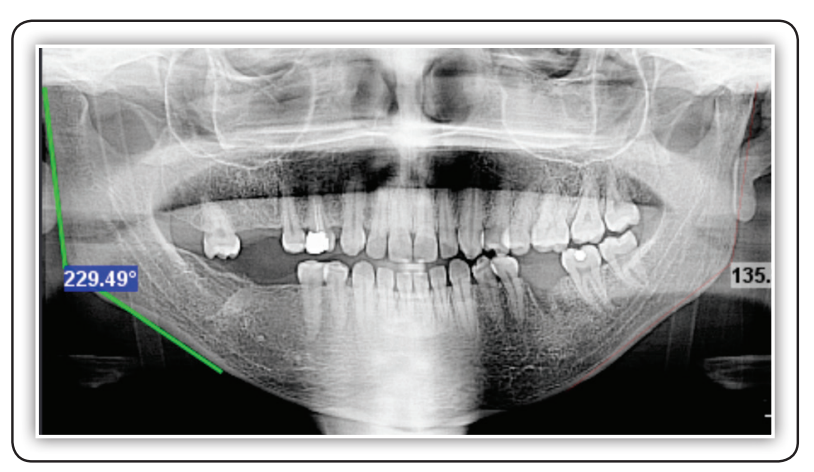

FIG (2) Panoramic view shows Gonial angle

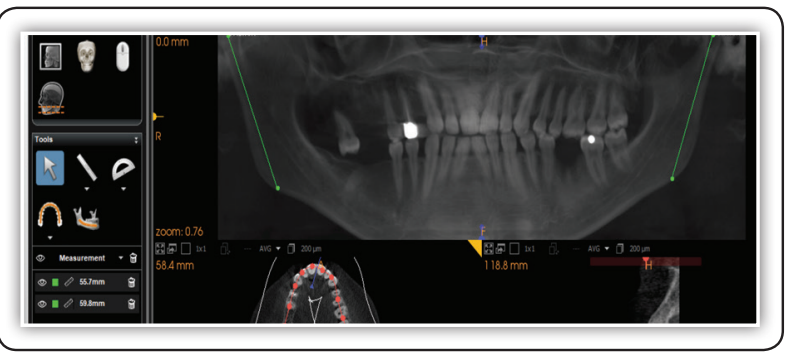

FIG (4) CBCT shows Ramus height

best performance for the test. Significance of the obtained results was judged at the $5 \%$ level.

\section{Comparison between CBCT and Panorama}

In ramous height and Gonial angel; CBCT showed a statistically significant difference compared to panoramic radiography while, in Bigonial width there is no statistically significant difference (table 1).

TABLE (1): Comparison between CBCT and Panorama

\begin{tabular}{lccc}
\hline & CBCT & Panorama & P \\
\hline Ramous height & $61.2 \pm 4.3$ & $70.8 \pm 6.7$ & $<0.001^{*}$ \\
Bigonial width & $164.1 \pm 16.0$ & $173.8 \pm 24.3$ & 0.237 \\
Gonial angel & $132.1 \pm 5.4$ & $232.1 \pm 2.5$ & $<0.001^{*}$ \\
\hline
\end{tabular}

Normally quantitative data was expressed in mean $\pm S D$ $p: p$ value for Paired $t$-test for comparing between CBCT and Panorama

*: Statistically significant at $p \leq 0.05$ 
2. Relation between Ramous height, Bigonial width and gonial angel with sex

Regarding Ramous height, Bigonial width and Gonial angel; CBCT showed a statistically significant difference compared to panoramic radiography and was able to differentiate between males and females.

TABLE (2): Relation between sex with Ramous height, Bigonial width and gonial angel

\begin{tabular}{lccc}
\hline & Males & Females & P \\
\hline Ramous height & & & \\
CBCT & $59.5 \pm 3.0$ & $63.6 \pm 5.0$ & $0.033^{*}$ \\
Panorama & $70.4 \pm 5.2$ & $71.3 \pm 8.8$ & 0.776 \\
$\begin{array}{l}\text { Bigonial width } \\
\text { CBCT }\end{array}$ & $154.0 \pm 6.0$ & $179.3 \pm 14.1$ & $0.030^{*}$ \\
Panorama & $171.2 \pm 24.2$ & $177.8 \pm 27.6$ & 0.700 \\
Gonial angel & & & \\
CBCT & $127.3 \pm 3.4$ & $132.3 \pm 4.0$ & $<0.001^{*}$ \\
Panorama & $225.7 \pm 2.6$ & $231.1 \pm 2.2$ & 0.188 \\
\hline
\end{tabular}

Normally quantitative data was expressed in mean \pm SD $p: p$ value for Student t-test for comparing between the two groups

*: Statistically significant at $p \leq 0.05$

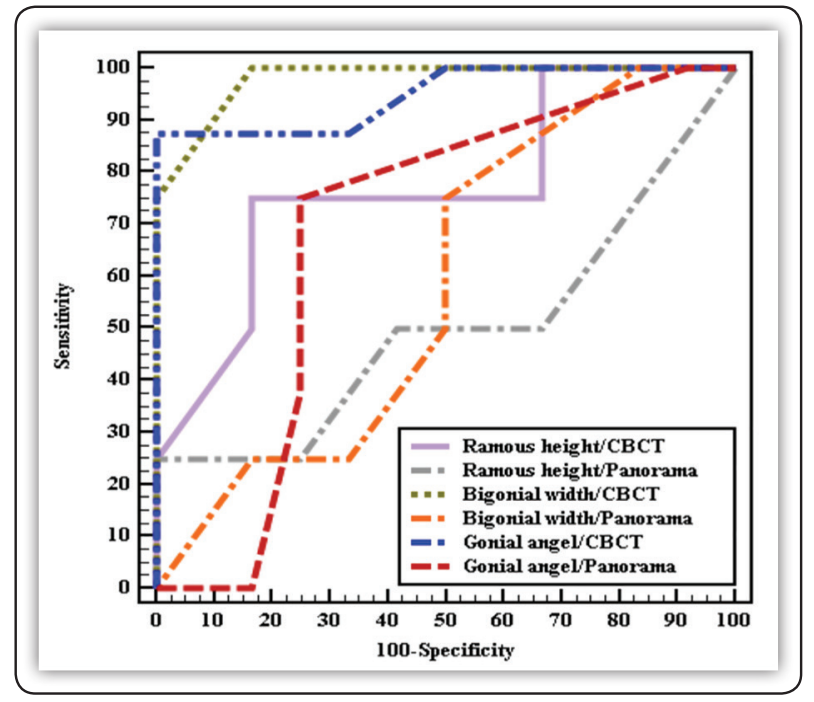

FIG (6) ROC curve for ramous height, Bigonial width and gonial angel to diagnose females from males

\section{Agreement (sensitivity, specificity) for ramous height, Bigonial width and gonial angel to diag- nose females from males}

In this regard, Ramous height, Bigonial width and Gonial angel showed higher Sensitivity and Specificity to differentiate between males and females on CBCT.

TABLE (3): Agreement (sensitivity, specificity) for ramous height, Bigonial width and gonial angel to diagnose females from males

\begin{tabular}{|c|c|c|c|c|c|c|c|c|c|}
\hline & \multirow{2}{*}{ AUC } & \multirow{2}{*}{$\mathbf{P}$} & \multicolumn{2}{|c|}{$95 \%$ C. I } & \multirow{2}{*}{ Cut off } & \multirow{2}{*}{ Sensitivity } & \multirow{2}{*}{ Specificity } & \multirow{2}{*}{ PPV } & \multirow{2}{*}{ NPV } \\
\hline & & & $\mathbf{L L}$ & $\mathbf{U L}$ & & & & & \\
\hline \multicolumn{10}{|l|}{ Ramous height } \\
\hline $\mathrm{CBCT}$ & $0.771^{*}$ & $0.045^{*}$ & 0.548 & 0.993 & $>61.5$ & 75.0 & 83.33 & 75.0 & 83.3 \\
\hline Panorama & 0.500 & 1.000 & 0.216 & 0.784 & $>71.4$ & 50.0 & 58.33 & 44.4 & 63.6 \\
\hline \multicolumn{10}{|l|}{ Bigonial width } \\
\hline $\mathrm{CBCT}$ & 0.979 & $0.014^{*}$ & 0.900 & 1.0 & $>155$ & 100.0 & 83.33 & 80.0 & 100.0 \\
\hline Panorama & 0.583 & 0.670 & 0.214 & 0.952 & $>161$ & 75.0 & 50.0 & 50.0 & 75.0 \\
\hline \multicolumn{10}{|l|}{ Gonial angel } \\
\hline $\mathrm{CBCT}$ & $0.948^{*}$ & $0.001^{*}$ & 0.841 & 1.0 & $\geq 132$ & 87.50 & 66.67 & 63.6 & 88.9 \\
\hline Panorama & 0.682 & 0.177 & 0.435 & 0.930 & $\geq 231$ & 75.0 & 75.0 & 66.7 & 81.8 \\
\hline
\end{tabular}

AUC: Area Under a Curve p value: Probability value CI: Confidence Intervals

NPV: Negative predictive value PPV: Positive predictive value *: Statistically significant at $p \leq 0.05$ 


\section{Relation between age with ramous height, Bi-} gonial width and gonial angel

Ramous height, Bigonial width and Gonial angel on CBCT showed a statistically significant difference compared to panoramic radiography in determination of age.

TABLE (4): Relation between age with ramous height, Bigonial width and gonial angel

\begin{tabular}{cccc}
\hline & \multicolumn{2}{c}{ Age group } & \multirow{2}{*}{ P } \\
\cline { 2 - 3 } & \multicolumn{2}{c}{$<\mathbf{3 0}$} & \multicolumn{3}{c}{} & \\
\hline Ramous height & & & \\
CBCT & $63.9 \pm 4.7$ & $59.3 \pm 3.0$ & $0.017^{*}$ \\
Panorama & $69.5 \pm 7.8$ & $71.6 \pm 6.0$ & 0.504 \\
Bigonial width & & & \\
CBCT & $174.6 \pm 14.7$ & $157.1 \pm 12.1$ & $0.009^{*}$ \\
Panorama & $171.4 \pm 19.4$ & $175.4 \pm 26.8$ & 0.719 \\
Gonial angel & & & \\
CBCT & $128.8 \pm 3.1$ & $134.3 \pm 5.6$ & $0.019^{*}$ \\
Panorama & $225.4 \pm 2.4$ & $232.5 \pm 2.6$ & 0.342 \\
\hline
\end{tabular}

Normally quantitative data was expressed in mean $\pm S D$ $p: p$ value for Student t-test for comparing between the two groups

*: Statistically significant at $p \leq 0.05$

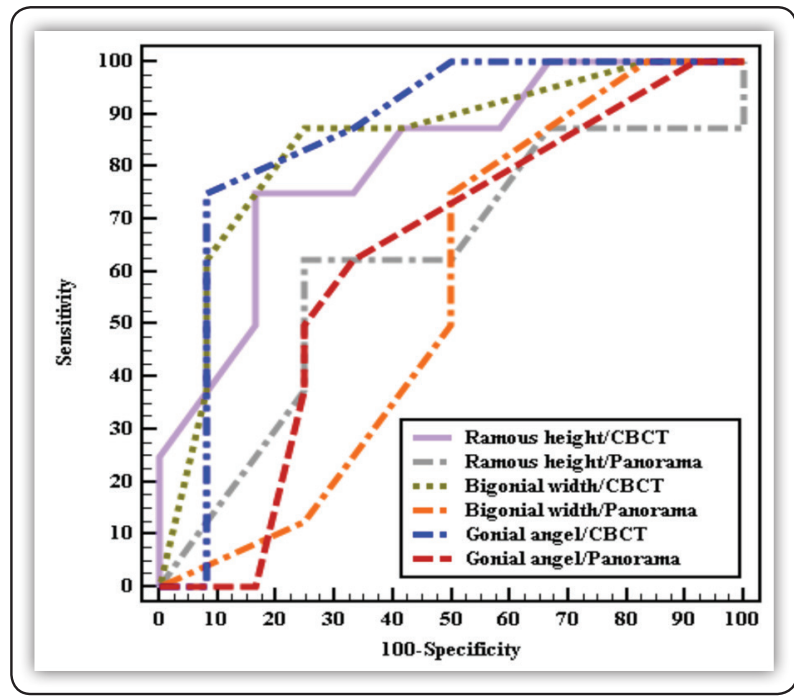

FIG (7) ROC curve for ramous height, Bigonial width and gonial angel to diagnose age group $\leq 30$ from $>30$

\section{Agreement (sensitivity, specificity) for ramous} height, Bigonial width and gonial angel to diagnose age group $\leq 30$ from $>30$

In Ramous height, Bigonial width and Gonial angel; CBCT showed higher Sensitivity and Specificity to diagnose age.

TABLE (5): Agreement (sensitivity, specificity) for ramous height, Bigonial width and gonial angel to diagnose age group $\leq 30$ from $>30$

\begin{tabular}{|c|c|c|c|c|c|c|c|c|c|}
\hline & \multirow{2}{*}{ AUC } & \multirow{2}{*}{$\mathbf{P}$} & \multicolumn{2}{|c|}{ 95\% C.I } & \multirow{2}{*}{ Cut off } & \multirow{2}{*}{ Sensitivity } & \multirow{2}{*}{ Specificity } & \multirow{2}{*}{ PPV } & \multirow{2}{*}{ NPV } \\
\hline & & & LL & UL & & & & & \\
\hline \multicolumn{10}{|l|}{ Ramous height } \\
\hline $\mathrm{CBCT}$ & $0.813^{*}$ & $0.021^{*}$ & 0.620 & 1.00 & $>61.5$ & 75.0 & 83.33 & 75.0 & 83.3 \\
\hline Panorama & 0.620 & 0.375 & 0.355 & 0.884 & $\leq 71.4$ & 62.5 & 50.0 & 45.5 & 66.7 \\
\hline \multicolumn{10}{|l|}{ Bigonial width } \\
\hline $\mathrm{CBCT}$ & $0.844^{*}$ & $0.011^{*}$ & 0.658 & 1.00 & $>155$ & 87.5 & 75.0 & 70.0 & 90.0 \\
\hline Panorama & 0.552 & 0.700 & 0.296 & 0.808 & $>161$ & 75.0 & 50.0 & 50.0 & 75.0 \\
\hline \multicolumn{10}{|l|}{ Gonial angel } \\
\hline $\mathrm{CBCT}$ & $0.859^{*}$ & $0.008^{*}$ & 0.682 & 1.0 & $\leq 132$ & 75.0 & 91.67 & 85.7 & 84.6 \\
\hline Panorama & 0.620 & 0.375 & 0.366 & 0.874 & $\leq 231$ & 62.50 & 66.67 & 55.6 & 72.7 \\
\hline
\end{tabular}

AUC: Area Under a Curve

NPV: Negative predictive value p value: Probability value

PPV: Positive predictive value
CI: Confidence Intervals

*: Statistically significant at $p \leq 0.05$ 


\section{DISCUSSION}

The identification of gender from human remains is of fundamental importance in forensic medicine and anthropology, especially in criminal investigations of missing persons and in attempts at reconstructing the lives of ancient population. One of the important aspects of forensics is to determine gender from fragmented jaws and dentition ${ }^{(30)}$. Mandible the most dimorphic, largest, strongest and movable part of the skull. Such morphological features play a vital role in sex determination in cases where intact skulls are not found ${ }^{(33,34)}$.

Mandible was used in this study for two simple reasons; firstly, there appears to be paucity of standards utilizing their morphological elements, and secondly, the bone is largely intact. Thus, in cases where intact skull is not found, mandible may play a vital role in sex determination ${ }^{(35)}$.

CBCT is useful in forensic contexts, offering several advantages for post-mortem forensic imaging including good resolution for skeletal imaging, relatively low cost, portability, and simplicity. 3D reconstruction, bite-mark analysis, age estimation, person identification and anthropological assessment using CBCT have shown promising results. (36) Panoramic radiographs have been advocated routinely as a one of the appropriate screening tools for diagnosis of oral diseases. The principal advantages of panoramic image are its broad coverage, low patient radiation dose, short time required for image acquisition and has been a very good source for retrospective studies. Several studies have been reported that panoramic radiographs are reproducible and accurate for the linear and angular measurements on mandibles. ${ }^{(37)}$

In the present study CBCT showed a statistically significant difference with panoramic radiography in Ramus height and gonial angel. ROC curve in $\mathrm{CBCT}$, when the ramous height was $>61.5 \mathrm{~mm}$ it indicates females. When the Bigonial width was $>155 \mathrm{~mm}$ it indicates females. When the Gonial angel was $\geq 132$ it indicates females. In the present study ROC curve for ramous height, Bigonial width and gonial angel to diagnose age group $\leq 30$ from $>30$. In CBCT, when the ramous height was $>61.5$ $\mathrm{mm}$ it indicates $\leq 30$. When the Bigonial width was $>155 \mathrm{~mm}$ it indicates $\leq 30$. When the Gonial angel was $\geq 132$ it indicates $\leq 30$.

Our results correlated with Huumonen et $\mathrm{al}^{(38)}$ who found significantly larger gonial angle in females as compared to males. Anupam Datta et $\mathrm{al}^{(39)}$ conducted a study in 50 adult mandibles to analyze sexual dimorphism in the mandible of South Indian population. They measured Gonial angle, Bigonial width, Height of ramus. The Gonial angle, Bigonial width, Height of ramus showed statistically significant gender difference.

Sinanoglu et al (40) in their CBCT study found that $\mathrm{CBCT}$ can be considered a method of choice for age estimation. Jodi Leversha et al ${ }^{(41)}$ determined a correlation of mandibular parameters with individual's age and gender in dentate subjects. They found that males were shown to have a larger ramus height and Bigonial width than females and females were shown to have larger Gonial angle than males. Our results were consistent with Daydas et al ${ }^{(42)}$ who reported mandibular ramus height to be the best parameter in the study, since our study showed significant difference between males and females. Study done by Dayal, et al. ${ }^{(43)}$ studied six mandibular measurements of South African Blacks and found that the average accuracy for gender determination varied from 80 to $85 \%$. The Bigonial width and mandibular ramus height measurements showed the highest accuracy of about $85.0 \%$.

Generally, it can be concluded from the present study that, Bigonial width and the Gonial angel on CBCT might differentiate females from males and predict different ages in a more superior and reliable way compared to panoramic view. 


\section{REFERENCES}

1. Drake, R. L.; Vogl, W. \& Mitchell, A. W. M. Gray's Anatomy for Students. 2nd ed. Philadelphia, Churchill Livingstone/Elsevier, 2010. pp.814-7.

2. Leversha, J.; McKeough, G.; Myrteza, A.; SkjellrupWakefiled H.; Welsh, J. \& Sholapurkar, A. Age and sex correlation of gonial angle, ramus height and bigonial width in dentate subjects in a dental school in Far North Queensland.J.Clin.Exp. Dent., 8(1):e49-e54, 2016.

3. Enlow DH, Bianco HJ, Eklund S. The remodeling of the edentulous mandible. J Prpsthet Dent. 1976;36:685-93.

4. Armaghan A, Haas DA, et al. Radiographic localization of mandibular anaesthesia landmarks. Oral. Surg, Oral Med, Oral Pathol, Oral Radiol, Endod. 1998;86(2):234-41.

5. Lambrechts AH, Harris AM, Rossouw PE, Stander I. Dimensional differences in the craniofacial morphologies of groups with deep and shallow mandibular antegonial notching. Angle Orthod. 1996;66:265-72.

6. Ashkenazi M, Taubman L, et al. Age associated changes of the mandibular foramen position in Anteroposterior dimension and of the mandibular angle in dry human mandibles. The Anatomical record. 2011;294:1319-25.

7. Tracy WE, Savara BS, Brant JWA. Relation of hight, width and depth of the mandible. The Angle Orthodontist 1965;35(4):269-77.

8. Saini V, Srivastava R, Rai RK, Shamal SN, Singh TB, Tripathi SK. Mandibular ramus: an indicator for sex in fragmentary mandible. Journal of forensic Sciences 2011; 56: $13-16$.

9. Ohm E, Silness J. Size of the mandibular jaw angle related to age, tooth retention and gender. J Oral Rehabil. 1999; 26:883-91.

10. Celyan G, Yanikoglu N, Yilaz AB, Ceylan Y. Changes in the mandibular angle in the dentulous and edentulous states. J Prosthet Dent 1998; 80:680-84.

11. Ronning O, Barnes SA, Pearson MH, Pledger DM. Juvenile chronic arthritis:acephalometric analysis of the facial skeleton. Eur J Orthod. 1994; 16: 53-62.

12. Raustia AM, Salonen MA, Pyhtinen J. Evaluation of masticatory muscles of edentulous patients by computed tomography and electromyography. J Oral Rehabil. 1996; 1: 11-16.

13. Casey DM, Emrich LJ. Changes in the mandibular angle in the edentulous state. J Prosthet Dent. 1988; 59: 373-80.

14. Fish SF. Change in the gonial angle. J Oral Rehabil. 1979; 6: 219-27.
15. Saglam AA, Sanli G. Condylar asymmetry measurements in patients with temporomandibular disorders. J Contemp Dent Pract. 2004; 5: 59-65.

16. Raustia AM, Salonen MA. Gonial angles and condylar ramus hight of the mandible in complete denture wearers-a panoramic radiograph study. J Oral Rehabil. 1997; 24: 512-16.

17. Sakar O, Sulun T, Ispirgil E. Correlation of the gonial angle size with residual ridge resorption in edentulous subjects. Balk J Stom, 2008; $12: 38-41$.

18. Lux CJ, Condradt C, Burde D, Komposch G. Dental arch widths and mandibular-maxillary base widths in Class 2 Malocclusion between early mixed and permanent dentitions. The Angle Orthodontist 2003; 73(6): 674-85

19. Shaw RBJr, katzel EB, Koltz PF, Khan DM, Girotto JA, Langstein HN. Aging of the mandible and its aesthetic implications. Plastic and Reconstructive Surgery 2010; 125(1): 332-42.

20. Arifin AZ, Asano A, Taguchi A, Nakamoto T, Ohtsuka M, Tanimoto K. Computer-aided system for measuring the mandibular cortical width on panoramic radiographs in osteoporosis diagnosis. Proc of SPIE 2005; 5747: 813-21.

21. Watanabe PCA, Issa JPM, Oliveira TM, Moteiro SAC, Iyomasa MM, SCH Siessere S Morphodigital study of the mandibular trabecular bone in panoramic radiographs. Int J Morphol 2007; 25(4): 875-80.

22. Yanez-vico RM, Iglesias-linares A, Torres-lagares D, Gutierrez-Perez JL, Solano-Reina E. Diagnostic of craniofacial asemmetry. Literature review. Med Oral Pathol Oral Cir Bucal 2010; 15(3): 494-98.

23. Bssed RB, Briggs C, Drummer OH. Age estimation using $\mathrm{CT}$ imaging of the third molar tooth, the medial clavicular epiphysis, and the spheno-occipital synchondrosis: a multi-factorial approach. Forensic Sci Int 2011;212: 1-5

24. Von See C, Bormann KH, Schumann P, Goetz F, Gellrich NC, Rucker M. Forensic imaging of projectiles using cone-beam computed tomography. Forensic Sci Int 2009; 10(190): 38-41

25. Kane AA, Lo LJ, Chen YR, Hsu KH, Noordhoff MS. The course of the inferior alveolar nerve in the normal human mandibular ramus and in patients presenting for cosmetic reduction of the mandibular angles. Plast Reconstr Surg 2000; 106: 1162-74.

26. Lo LJ, Wong FH, Chen YR.the position of the inferior alveolar nerve at the mandibular angle: an anatomic consideration for a esthetic mandibular angle reduction. Ann Plast Surg 2004; 53: 50-55. 
27. Cutright B, Quillopa N, Schubert W. An anthropometric analysis of the key foramina for maxillofacial surgery. $\mathrm{J}$ Oral Maxillofac Surg 2003; 61 : 354-7.

28. Levine $\mathrm{MH}$, Goddard Al, Dodson TB. Inferior alveolar nerve canal position: a clinical and radiographic study. J Oral Maxillofac Surg 2007; 65: 470-4.

29. Mattila K, Altonin M, Haaviko K. Determination of the gonial angle from the orthopantomogram. Angle Orthod. 1977; 47: 107-110.

30. Scheuer L. Application of osteology to forensic medicine. ClinAnat2002; 15:297-312.

31. Williams PL, Bannister LG, Berry MM. Gray's Anatomy. 38th Ed, New York, Churchill Livingstone; 2000:40919Sci. 2011; 56(Suppl1):S13-6.

32. Franklin D, O'Higgins P, Oxnard CE, Dadour I. Discriminant function sexing of the mandible of Indigenous South Africans. Forensic Sci Int. 2008; 179:84.e1-5

33. Hu KS, Koh KS, Han SH, Shin KJ, Kim HJ. Sex determination using nonmetric characteristics of the mandible in Koreans. J Forensic Sci. 2006; 51:1376-8.

34. Humphrey LT, Dean MC, Stringer CB. Morphological variation in great ape and modern human mandibles. J Anat. 1999; 195:491-513

35. Saini V, Srivastava R, Rai RK, Shamal SN, Singh TB, Tripathi SK. Mandibular ramus: An indicator for sex in fragmentary mandible. J Forensic Sci 2011; 56 (Suppl1): S13-6.

36. Sujatha S., Rizwana Azmi S., Yashodha Devi B. K., Shwetha V. and Pavan Kumar T.. CBCT -The Newfangled in Forensic Radiology. Journal of Dental \& Oro-facial Research. 2017; 13: 47-55.

37. Indira AP, Markande A, David MP. Mandibular ramus: An indicator for sex determination - A digital radiographic study. J Forensic Dent Sci. 2012;4:58-62.

38. Hummoen -S. Huumonen, K. Sipil “ A, B. Haikola et al., "Influence of edentulousness on gonial angle, ramus and condylar height, "Journal of Oral Rehabilitation,vol. 37 no. 1, pp. 34-38, 2010.

39. Anupam Datta, Santhosh Chandrappa Siddappa, Viswanathan Karibasappa, Gowda Siddesh, Revapla Channabasappa, Satish Babu, Banagere Shivalingappa, Srijith, Debaleena Dey. Indian Journal of Forensic and Community Medicine, July - September 2015;2(3):158-166

40. Sinanoglu A, Demirturk H, Noujeim M. Age estimation by an analysis of spheno-occipital synchondrosis using conebeam computed tomography. Leg Med. 2016;18:13-9.

41. Jodi Leversha, Glen McKeough Adriana Myrteza , Hannah Skjellrup-Wakefiled Jordan Welsh , Amar Sholapurkar Age and gender correlation of mandibular parameters J Clin Exp Dent 2016:8(1):e49-54

42. B. Daydas, I. Yavuz, I. M. Da`gsuyu, B. Bölükbas’i, and I. Ceylan,"An investigation of maxillary and mandibular morphology in different overjet groups," Australian Orthodontic Journal, vol. 20, no. 1, pp. 11-18, 2004

43. Dayal MR, Spocter MA, Bidmos MA. An assessment of sex using the skull of black South Africans by discriminant function analysis. Homo. 2008;59(3):209-221. 